\title{
Effects of Soil Conditioners on Absorption of phosphorus by waxy corn and Phosphorus Transformation in High Phosphorus Soils
}

\author{
Wang Xi, Lu Shuchang*, Pei Zhiqiang , Hou Kun, Ya Zongjie, Zhang Yu,Wang Dafeng,and Li Xiawen \\ College of Agronomy and Resource Environment, Tianjin Agricultural University, Tianjin 300384, China
}

\begin{abstract}
In this experiment, the effects of different types of conditioners and their application on the absorption and transformation of phosphorus in high phosphorus soils in facilities were investigated to improve the environmental problems of protected farmland caused by phosphorus accumulation. Waxy corn was used as a test crop, and five conditioners such as humic acid, biochar, bentonite, alum, and dephosphorized gypsum were used as test materials for potting experiments. The experiment set 10 treatments, namely T1(Blank control), T2(Humic acid), T3(Biochar), T4(Bentonite), T5(Alum), T6 (Dephosphorized gypsum), T7(Biochar-bentonite-alum), T8(Humic acid-biochar-alum),T9(Humic acidbiochar-bentonite-alum),T10(Humic acid-bentonite-biochar-alum-dephosphorized gypsum). Based on the analysis of the results of the three crops, except that the first crop was not significant, the biomass and phosphorus absorption of waxy corn of T2 was the highest in the second crop, and T10 was the most effective treatment in the third crop. The soil available phosphorus content of T8 was the lowest in the second crop and that of T10 was the lowest in the third crop, which were $12.01 \%$ and $12.75 \%$ lower than the control. The soil water-soluble phosphorus content of T4 was the lowest in the second crop, which was $41.84 \%$ lower than the control, and that of T8 was the lowest in the third crop, which was $26.62 \%$ lower than the control. According to the results of the three crops, the ratio of the total phosphorus content of the inorganic phosphorus in the third crop of each treatment was increasing compared with the first crop. The soil phosphorus was transformed from organic phosphorus to inorganic phosphorus. The ratio of total phosphorus content of organic phosphorus of T6, T9, T10 was larger than other treatments, which slowed down the conversion of phosphorus to available form. The ratio of $\mathrm{Ca}_{8}-\mathrm{P}$ in the inorganic phosphorus was the highest, reaching about $50 \%$ to $60 \%$. From the results and analysis, T2 and T10 were beneficial to the absorption of soil phosphorus by waxy corn, T8 and T10 were beneficial to slow down the conversion of phosphorus to the effective state, reduce the potential risk of phosphorus environment, improve the phosphorus accumulation environmental issues in greenhouse farmland.
\end{abstract}

\section{Introduction}

With the continuous adjustment of China's agricultural planting structure, the vegetable industry had developed rapidly, and the planting area of facility vegetables had also increased significantly in northern China. Greenhouse vegetable scale production had become a pillar industry for increasing income of a large number of farmers in the northern region ${ }^{[1]}$.Phosphorus is one of the essential nutrients for crop growth ${ }^{[2]}$, and it affects crop growth and yield. Farmers applied large amounts of phosphate fertilizer to the soil in order to increase crop yield and get high benefits. As a result, the amount of phosphate fertilizer applied was much larger than the phosphorus required for vegetable growth. Excess phosphorus was enriched in the soil, and might enter water through runoff and leaching, which did not only reduce the utilization of phosphate fertilizer, but also caused environmental problems such as eutrophication of water bodies ${ }^{[3]}$. Therefore, it was important to solve the problem of non-point source pollution caused by phosphorus accumulation in greenhouse farmland. The soil conditioners were divided into three categories: Nutrient conditioners based on improving soil properties and beneficial for nutrient element absorption, environmental element passivating conditioners based on environmental risk control, and coordinating conditioners based on nutrient absorption and environmental element movement ${ }^{[4]}$.According to the current status of soil phosphorus environment in greenhouse farmland, humic acid, biochar, bentonite, alum and dephosphorized gypsum were selected as test conditioners in this experiment. Biochar had a large specific surface area and a well-developed pore structure, and had rich surface functional groups, which could adsorb phosphorus in the soil and reduce its mobility in the soi ${ }^{[5-8]}$.Bentonite was a kind of clay rock with montmorillonite as the main component, which had a large specific surface area and adsorption performance. It had strong adsorption, swelling and cation exchange capacity. When applied to the soil, it could retain soil nutrients and Restraint ${ }^{[9]}$.Alum was rich in aluminum ions. Studies had found that aluminum salts could effectively fix soil active phosphorus ${ }^{[10,11]}$.The main

\footnotetext{
*orresponding author: 1sc9707@163.com
} 
component of dephosphorized gypsum was calcium sulfate, which had the potential for phosphorus fixation ${ }^{[12]}$.Humic acid was a natural organic substance with redox and adsorption properties. It could promote the growth of roots and improve the absorption of phosphorus from soil by crops ${ }^{[13-15]}$.In recent years, domestic and foreign scholars had rich research on the effects of these kinds of conditioners on phosphorus, but there are few reports on the combination of these kinds of conditioners. Therefore, this experiment combined the application of these conditioning agents to study the effect on soil phosphorus conversion and absorption. The root system of most vegetables grown in greenhouse farmland was shallow ${ }^{[16]}$. Some studies had proposed that planting deep-root catch crops during the leisure season could improve the utilization rate of phosphorus in deep soil by crops to reduce the loss of soil phosphorus. In view of this, this paper intended to use a deep-rooted crop of catch waxy corn as a test crop by a pot experiment. Five conditioning agents including humic acid, biochar, bentonite, alum, and dephosphorized gypsum were used in combination. The purpose was to study: if (1) the effects of different soil conditioners on the biomass and phosphorus absorption of waxy corn; (2)the effects of different soil conditioners on the phosphorus absorption and transformation of soil. It provided a theoretical basis for the planting of catch crops with conditioning application to solve the problem of phosphorus non-point source pollution.

\subsection{Test materials}

The experiment was conducted in the Environmental Science Laboratory of Tianjin Agricultural College from May 2017 to August 2018. The tested soil was collected from $0 \sim 20 \mathrm{~cm}$ surface soil of vegetable field intensive facilities in Houyouzhuang Village, Damengzhuang Town, Wuqing District, Tianjin. The basic physical and chemical properties of the soil were shown in Table 1. The soil texture was medium soil, the soil phosphorus content was high, and the phosphorus accumulation was serious. In the experiment, waxy corn 'Xuenuo 2' was used as the test crop, and humic acid, biochar (rice straw charcoal), bentonite, alum, and dephosphorized gypsum were used as test conditioners. The basic properties of the test conditioner were shown in Table 2.

Table 1. Basic physical and chemical properties of the tested soil

\begin{tabular}{|c|c|}
\hline Index & Contents \\
\hline Total phosphorus g/kg & 5.29 \\
\hline Available phosphorus $\mathrm{mg} / \mathrm{kg}$ & 603.16 \\
\hline Water-soluble phosphorus $\mathrm{mg} / \mathrm{kg}$ & 21.14 \\
\hline Organic matter $\mathrm{g} / \mathrm{kg}$ & 28.80 \\
\hline $\mathrm{pH}$ & 7.01 \\
\hline Texture & medium soil \\
\hline
\end{tabular}

\section{Materials and methods}

Table 2. Basic properties of the test conditioner

\begin{tabular}{|c|c|c|c|c|c|c|}
\hline Material & Source & $\begin{array}{c}\text { Total } \\
\text { nitrogen } \\
\text { g/kg }\end{array}$ & $\begin{array}{c}\text { Total } \\
\text { phosphorus } \\
\mathrm{g} / \mathrm{kg} \\
\end{array}$ & $\begin{array}{c}\text { Total } \\
\text { potassium } \\
\mathrm{g} / \mathrm{kg} \\
\end{array}$ & $\begin{array}{c}\text { Organic } \\
\text { carbon } \\
\mathrm{g} / \mathrm{kg}\end{array}$ & $\mathrm{pH}$ \\
\hline Humic acid & $\begin{array}{l}\text { Tianjin humeite interna- } \\
\text { tional trading Co., LTD }\end{array}$ & 4.73 & 4.37 & 0.59 & 4.12 & 4.85 \\
\hline Bio-charcoal & NingHe forest farm & 4.55 & 4.30 & 4.88 & 4.95 & 8.30 \\
\hline Bentonite & China Agricultural University & -- & 1.95 & 2.25 & -- & 8.54 \\
\hline Alum & Shandong Dongtai Company & -- & 1.84 & 61.53 & -- & 2.50 \\
\hline $\begin{array}{c}\text { Dephosphorization } \\
\text { gypsum }\end{array}$ & Shandong Dongtai Company & -- & 2.29 & 0.18 & -- & 6.31 \\
\hline
\end{tabular}


Table 3. Test design treatments (g/pot)

\begin{tabular}{|c|c|c|c|c|c|c|c|c|c|c|}
\hline Conditioner & $\mathrm{T} 1$ & $\mathrm{~T} 2$ & $\mathrm{~T} 3$ & $\mathrm{~T} 4$ & $\mathrm{~T} 5$ & $\mathrm{~T} 6$ & $\mathrm{~T} 7$ & $\mathrm{~T} 8$ & $\mathrm{~T} 9$ & $\mathrm{~T} 10$ \\
\hline Humic acid & $/$ & 3.13 & $/$ & $/$ & $/$ & $/$ & $/$ & 1.03 & 0.78 & 0.63 \\
\hline Bio-charcoal & $/$ & $/$ & 50 & $/$ & $/$ & $/$ & 16.66 & 16.66 & 12.50 & 10.00 \\
\hline Bentonite & $/$ & $/$ & $/$ & 25 & $/$ & $/$ & 8.34 & $/$ & 6.25 & 5.00 \\
\hline Alum & $/$ & $/$ & $/$ & $/$ & 4.69 & $/$ & 1.56 & 1.56 & 1.17 & 0.94 \\
\hline $\begin{array}{c}\text { Dephosphorization } \\
\text { gypsum }\end{array}$ & $/$ & $/$ & $/$ & $/$ & $/$ & 4.69 & $/$ & $/$ & $/$ & 0.94 \\
\hline
\end{tabular}

of ammonium vanadyl molybdate reagent, the volume

\subsection{Test plan}

The collected soil samples were air-dried and passed through a $5 \mathrm{~mm}$ sieve. The test conditioner was weighed according to the experimental design and thoroughly mixed with the soil, and then placed in a pot with a height of $17.4 \mathrm{~cm}$ and a caliber of $24.3 \mathrm{~cm}$. Each pot contained $5 \mathrm{~kg}$ of soil. The test was set up with 10 treatments, namely T1(Blank control, no conditioner applied), T2(Humic acid), T3(Biochar), T4(Bentonite), T5(Alum), T6 (Dephosphorized gypsum), T7(Biocharbentonite-alum),T8(Humicacid-biochar-alum),T9(Humic acid-biochar-bentonite-lum),T10(Humic acid-bentonitebiochar-alum-dephosphorized gypsum) as shown in Table 3 below. The per treatment had 3 replicates. Three waxy corns were planted in each pot, and two strong plants were left in each pot after emergence. The waxy corns were irrigated every 2 days during irrigation. The irrigation amount was $600 \sim 800 \mathrm{~mL}$ per pot, and nitrogen fertilizer was applied once at each jointing stage. $2.17 \mathrm{~g}$ of urea $(46 \% \mathrm{~N})$ was applied per pot.

\subsection{Sample collection and index determination method}

\subsubsection{Plant Sample Collection}

When waxy corn was harvested, the roots of waxy corn were pulled out of the pot, the roots were washed, and the whole plant was placed in an oven at $105^{\circ} \mathrm{C}$ for half an hour, then dried at $80^{\circ} \mathrm{C}$ to constant weight, and the dry biomass was measured. Then it was crushed and sieved to determine the total phosphorus content and calculate the phosphorus absorption of the plant.

\subsubsection{Soil sample collection}

After harvesting waxy corn, a soil sample was collected from each pot, and the soil sample was air-dried and sieved to determine the total phosphorus, available phosphorus, water-soluble phosphorus, and inorganic phosphorus components of the soil sample.

\subsubsection{Index measurement method}

Determination of plant samples: Plant phosphorus was digested by heating with $\mathrm{H}_{2} \mathrm{SO}_{4}$ and $\mathrm{H}_{2} \mathrm{O}_{2}$, and the digestion solution was made up to a $100 \mathrm{~mL}$ volumetric flask with distilled water. A certain amount of filtered digestion solution was pipette into a $50 \mathrm{~mL}$ volumetric flask, and 2 drops of 2,6-dinitrophenol indicator was added to solution. It was neutralized with sodium hydroxide, until it was just yellow. After adding $10 \mathrm{~mL}$ was reached with distilled water. After 15 minutes of color development, the coloring solution was measured $450 \mathrm{~nm}$ on a UV spectrophotometer.

Determination of soil samples: The available phosphorus in the soil was extracted with $0.5 \mathrm{~mol} / \mathrm{L}$ $\mathrm{NaHCO}_{3}$, the clear filtrate was extracted and developed with molybdenum antimony anti-reagent for 30 minutes, and then measured with a spectrophotometer at $700 \mathrm{~nm}$. The water-soluble phosphorus in the soil was extracted with $0.01 \mathrm{~mol} / \mathrm{L} \mathrm{CaCl}_{2}$, the clear filtrate was extracted and developed with a molybdenum antimony reagent for 30 minutes, and then measured with a spectrophotometer at $700 \mathrm{~nm}$.

The total phosphorus in the soil was digested by heating with $\mathrm{H}_{2} \mathrm{SO}_{4}$ and $\mathrm{HClO}_{4}$. The digestion solution used molybdenum and antimony to resist color development. The spectrophotometer was used to determine the total phosphorus content in the soil.

Soil inorganic phosphorus composition was determined according to the northern calcareous soil method of Jiang Baifan-Gu Yichu ${ }^{[17]}$.

\subsection{Data processing}

Phosphorus absorption of waxy corn $=$ dry biomass $\times$ total phosphorus content $(1)$

Inorganic phosphorus (or organic phosphorus) as a percentage of total phosphorus content

= inorganic phosphorus content (or organic phosphorus content) / total soil phosphorus content of foundation soil $\times 100 \%(2)$

The test data was processed by Excel 2010 method, and statistical analysis was performed by DPS7.05 software.

\section{Results and analyses}

\subsection{Biomass and phosphorus absorption of waxy maize treated with different soil conditioners}

\subsubsection{Effects of different treatments on the biomass of waxy corn}

Figure 1 showed the dry biomass of waxy corn under different conditioners. As shown in the figure, for the dry biomass of the first crop of waxy corn, T8 had the highest dry biomass, followed by $\mathrm{T} 1$, and there was no significant difference between the treatments; In the second crop, T2 had the highest dry biomass per pot, significantly higher than $\mathrm{T} 5$ and $\mathrm{T} 10$, but there was no 
significant difference with other treatments, followed by T6 and T7. In the third crop, T10 had the highest dry biomass per pot, significantly higher than T1, T5, and T8, which was $47.8 \%$ higher than $\mathrm{T} 1$, followed by $\mathrm{T} 4$ and $\mathrm{T} 2$. Based on the combined dry biomass of waxy corn, T2 and $\mathrm{T} 10$ had better effects.

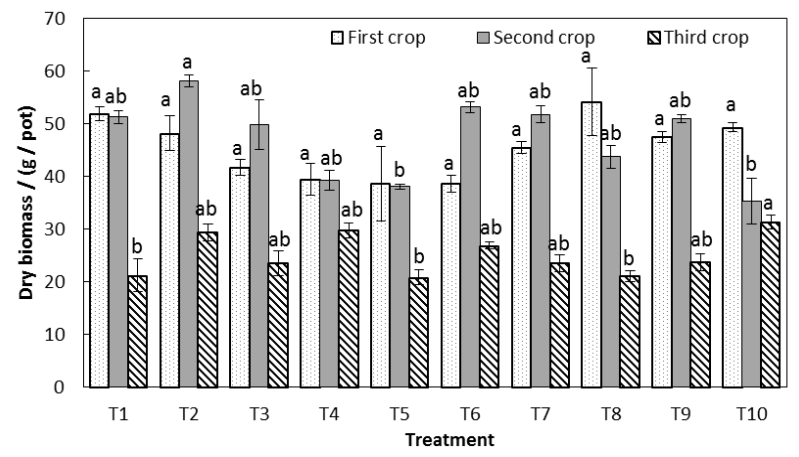

Fig.1. Biomass status of waxy corn under different treatments

[Note: Different lowercase letters indicated significant differences at the $5 \%$ level.]

\subsubsection{Effect of different treatments on phosphorus absorption of waxy corn}

Figure 2 showed the phosphorus absorption of waxy corn with different conditioners. It could be seen from the figure that among the first crops of waxy maize phosphorus absorption, T2 phosphorus absorption was the highest, which was $8.49 \%$ higher than T1, except that it was significantly higher than $\mathrm{T} 6$, and there was no significant difference with other treatments; In the second crop, the absorption of phosphorus by waxy corn was $\mathrm{T} 2$, followed by $\mathrm{T} 8$. There was no significant difference between the two treatments, which were $17.53 \%$ and $14.05 \%$ higher than $\mathrm{T} 1$, respectively; The third crop had the highest phosphorus absorption, which was significantly higher than $\mathrm{T} 1$ and $\mathrm{T} 8,58.38 \%$ higher than T1, followed by T6 and T4. Comprehensively combining the three crops of phosphorus absorption of waxy corn, T2 and T10 had better effects, promoted the absorption of phosphorus by waxy corn, and improved the utilization rate of phosphorus.

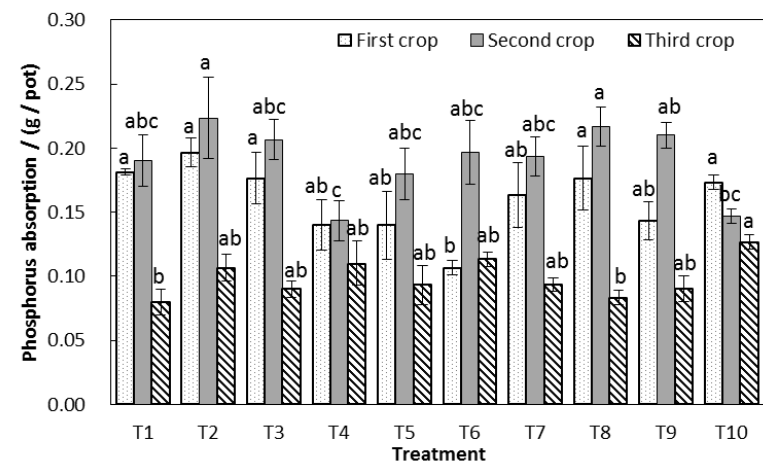

Fig.2. Phosphorus absorption status of waxy corn under different treatments

\subsection{Effects of different treatments on soil phosphorus}

\subsubsection{Effects of different treatments on soil available phosphorus}

Soil available phosphorus was a phosphorus source that could be directly absorbed and utilized by plants, and was the most rapid part of soil phosphorus pools for plant growth ${ }^{[18]}$. Therefore, to a certain extent, soil available phosphorus could reflect the extent to which plants absorb phosphorus from the soil. Figure 3 showed the available phosphorus content in the soil with different conditioners. It could be seen from the figure that the available phosphorus in the soil treated with the conditioner in the first crop was significantly higher than $\mathrm{T} 1$, except that there was no significant difference between T9 and T1. Among them, the soil of T4 had the highest available phosphorus content, which was $27.53 \%$ higher than T1. In the second crop, T6, T8 and T10 were significantly lower than $\mathrm{T} 1$. The soil of $\mathrm{T} 9$ had the highest available phosphorus content, which was $1.79 \%$ higher than $\mathrm{T} 1$, and the soil of $\mathrm{T} 10$ had the lowest available phosphorus content, which was $12.01 \%$ lower than T1. In the third crop, the treatments with conditioners were all lower than $\mathrm{T} 1$. The soil of $\mathrm{T} 8 \mathrm{had}$ the lowest available phosphorus content, which was $12.75 \%$ lower than $\mathrm{T} 1$, followed by $\mathrm{T} 4$, which was $11.78 \%$ lower than $\mathrm{T} 1$, and there was no significant difference between the two treatments. Based on the results of three crops, the available phosphorus content in soil under T8 and T10 was the lowest compared with other treatments.

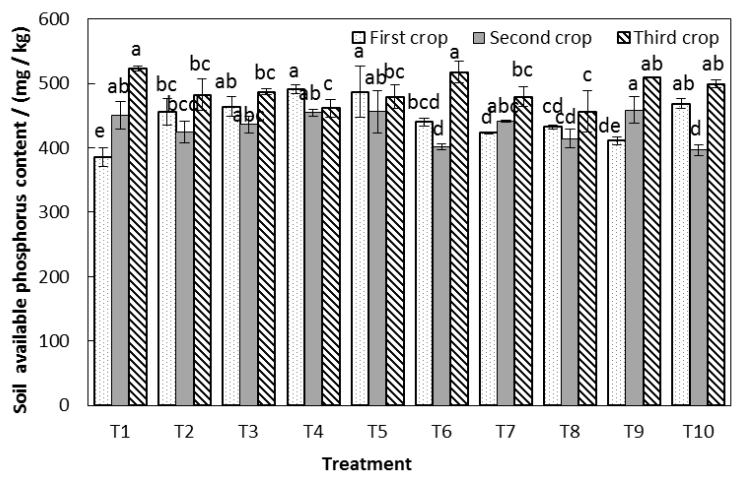

Fig. 3 . Status of available phosphorus in soil under different conditioning agents

\subsubsection{Effects of different treatments on soil water- soluble phosphorus}

Water-soluble phosphorus was part of soil total phosphorus, and it was also part of soil available phosphorus. It could dissolve in water ${ }^{[19,20]}$, and it could not only be used as an effective regular analysis indicator of soil ${ }^{[21]}$, but also could represent phosphorus environmental conditions, assessing the environmental risk of phosphorus in farmland. Figure 4 showed the water-soluble phosphorus content of the soil under 
different conditioners. As shown in the figure, after the first crop of waxy corn, the water-soluble phosphorus content in the soil of T2, T3, T6, T7, and T9 was significantly higher than that of $\mathrm{T} 1$, and the content of T6 was the highest, which was $30.72 \%$ higher than T1. The water-soluble phosphorus content in the soil of T4 and $\mathrm{T} 8$ was significantly lower than $\mathrm{T} 1$, and there was no significant difference between the two treatments, which were $41.84 \%$ and $38.04 \%$ lower than T1. After the second crop, there was no significant difference between the treatments applied with the conditioners and T1.The water-soluble phosphorus content in the soil was generally low due to the planting time of the second crop and the temperature environment. In the third crop, the soil water-soluble phosphorus content of the treatments applied with the conditioners was lower than T1. T4, T5, and $\mathrm{T} 8$ were significantly lower than $\mathrm{T} 1$, and the contents were $26.62 \%, 17.58 \%$, and $20.11 \%$ lower than $\mathrm{T} 1$. In general, the soil water-soluble phosphorus content of T4 and T8 was lower than that of other treatments.

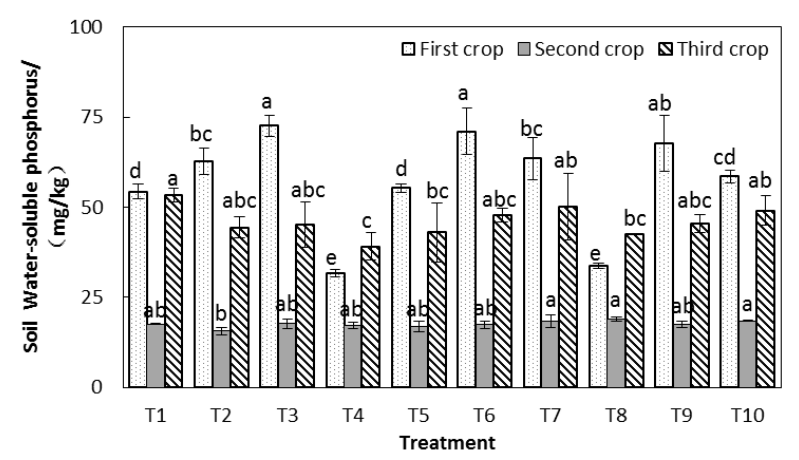

Fig.4. Water-soluble phosphorus in soil under different conditioning agents

\subsubsection{Effects of different treatments transformation of soil phosphorus forms}

on

\subsubsection{Effects of different treatments on transformation of soil inorganic phosphorus and organic phosphorus}

Phosphorus mainly existed in the soil in two forms: inorganic phosphorus and organic phosphorus, both of which cooperate and restrict each other [22]. Organic phosphorus in soil needed to be mineralized and decomposed into inorganic phosphorus before it could be absorbed and used by plants ${ }^{[23]}$. Table 4 showed the percentages of inorganic phosphorus and organic phosphorus in the total phosphorus content of the basic sample. As can be seen from the table, in the first crop, compared with $\mathrm{T} 1$, the ratio of inorganic phosphorus to total phosphorus in each treatment with the conditioner was reduced, indicating that the application of the conditioner promoted the conversion of inorganic phosphorus to organic phosphorus and inhibited phosphorus in the soil of the mineralization, the effect was more obvious was T6. In the second crop, except for the proportion of T5 and T8 inorganic phosphorus which was higher than $\mathrm{T} 1$, other treatments were lower than $\mathrm{T} 1$.
T5 and T8 promoted the conversion of organic phosphorus to inorganic phosphorus form, and the other was the opposite. The most obvious effect was T4. In the third crop, except for T3 and T5, which accounted for more than $\mathrm{T} 1$, the other treatments were lower than $\mathrm{T} 1$. T3 and T5 promoted the conversion of organic phosphorus to inorganic phosphorus, and the other treatments did the opposite. The most obvious effect was T10. As for the results of the three crops, compared with the first crop, the percentage of total phosphorus content in the third crop of each treatment increased continuously. The soil was transformed from organic phosphorus to inorganic phosphorus. T6, T9, T10 Compared with other treatments, the proportion of organic phosphorus in total phosphorus was larger, which slowed down the transformation of phosphorus to effective form.

Table 4. Percentage of total phosphorus content in inorganic phosphorus

\begin{tabular}{|c|c|c|c|}
\hline \multirow{2}{*}{ Treatment } & \multicolumn{3}{|c|}{ Inorganic phosphorus/ Total phosphorus(\%) } \\
\cline { 2 - 4 } & First crop & Second crop & Third crop \\
\hline T1 & 71.41 & 76.03 & 80.57 \\
\hline T2 & 70.09 & 70.82 & 78.34 \\
\hline T3 & 65.75 & 74.37 & 81.55 \\
\hline T4 & 69.12 & 69.20 & 78.47 \\
\hline T5 & 70.65 & 77.03 & 86.30 \\
\hline T6 & 63.37 & 75.87 & 74.82 \\
\hline T7 & 71.27 & 75.19 & 75.83 \\
\hline T8 & 69.13 & 76.16 & 75.65 \\
\hline T9 & 66.98 & 70.92 & 74.76 \\
\hline T10 & 65.74 & 74.98 & 71.93 \\
\hline
\end{tabular}

\subsubsection{Effects of different treatments on internal phosphorus transformation in soil}

Soil inorganic phosphorus was an important component of soil phosphorus, accounting for about $50 \%$ to $80 \%$ of total soil phosphorus ${ }^{[24,25]}$. The availability of soil phosphorus was determined by the content, form, and transformation of inorganic phosphorus. Based on the grading system of inorganic phosphorus forms of calcareous soil by Jiang Baifan and Gu Yichu ${ }^{[26]}$, the inorganic phosphorous of calcareous soil was divided into dicalcium phosphate $\left(\mathrm{Ca}_{2}-\mathrm{P}\right)$, octacalcium phosphate $\left(\mathrm{Ca}_{8}-\mathrm{P}\right)$, and ten phosphate Calcium salts $\left(\mathrm{Ca}_{10}-\mathrm{P}\right)$, aluminum phosphates (Al-P), iron phosphates (Fe-P), and sequestered phosphorus (O-P). It could be seen from Table 5 that the proportion of $\mathrm{Ca}_{8}-\mathrm{P}$ in the inorganic phosphorus components of the first crop soil was the largest, ranging from $54.35 \%$ to $60.75 \%$; secondly, Fe-P accounted for about $11.94 \%$ to $16.45 \%$ of the total inorganic phosphorus content; $\mathrm{Ca}_{10}-\mathrm{P}$ accounted for $9.47 \%$ to $15.87 \%$; $\mathrm{Ca}_{2}-\mathrm{P}$ accounted for $7.28 \%$ to $8.59 \%$ of the total inorganic phosphorus content; Al-P 
accounted for $5.78 \%$ to $7.46 \%$ of the total inorganic phosphorus content; and O-P only accounts for inorganic The total phosphorus content was $1.48 \%$ to $1.94 \%$. In the second stubble soil, the content of $\mathrm{Ca}_{8}-\mathrm{P}$ in inorganic phosphorus of the soil was $59.83 \%$ to $69.46 \%$; secondly, Fe-P accounted for about $12.93 \%$ to $16.26 \%$ of the total content of inorganic phosphorus; $\mathrm{Ca}_{2}-\mathrm{P}$ accounted for approximately $4.70 \%$ to $6.62 \%$ of the total inorganic phosphorus content; Al-P accounted for $2.89 \%$ to $4.16 \%$ of the total inorganic phosphorus content; and O-P only accounted for $0.74 \%$ to $2.08 \%$ of the total inorganic phosphorus content. The $\mathrm{Ca}_{8}-\mathrm{P}$ in the third soil inorganic phosphorus was $55.50 \%$ to $65.94 \%$. Fe-P accounts for $11.48 \%$ to $13.76 \%$ of the total inorganic phosphorus content. The proportion of $\mathrm{Ca}_{10}-\mathrm{P}$ was $9.24 \%$ to $15.61 \%$. The total content of $\mathrm{Ca}_{2}-\mathrm{P}$ was $5.87 \%$ to $8.47 \%$. Al-P accounted for about $4.07 \%$ to $5.92 \%$ of the total inorganic phosphorus content. However, O-P only accounted for $0.97 \%$ to $1.81 \%$ of the total inorganic phosphorus content.

Table 5. Percentage of total inorganic phosphorus in each component of inorganic phosphorus under different treatments(\%)

\begin{tabular}{|c|c|c|c|c|c|c|c|}
\hline Stubble & Treatment & $\mathrm{Ca}_{2}-\mathrm{P}$ & $\mathrm{Ca}_{8}-\mathrm{P}$ & $\mathrm{Ca}_{10}-\mathrm{P}$ & Al-P & Fe-P & O-P \\
\hline \multirow{10}{*}{$\begin{array}{l}\text { First } \\
\text { crop }\end{array}$} & $\mathrm{T} 1$ & 7.55 & 60.52 & 10.39 & 6.45 & 13.36 & 1.73 \\
\hline & $\mathrm{T} 2$ & 8.15 & 57.23 & 10.45 & 5.78 & 16.45 & 1.94 \\
\hline & T3 & 7.45 & 60.75 & 9.47 & 6.32 & 14.36 & 1.65 \\
\hline & $\mathrm{T} 4$ & 8.06 & 54.35 & 12.92 & 6.36 & 16.44 & 1.87 \\
\hline & $\mathrm{T} 5$ & 8.59 & 56.70 & 12.00 & 6.49 & 14.52 & 1.71 \\
\hline & T6 & 7.28 & 56.49 & 12.72 & 7.40 & 14.18 & 1.93 \\
\hline & $\mathrm{T} 7$ & 7.71 & 56.46 & 13.10 & 5.92 & 15.13 & 1.68 \\
\hline & $\mathrm{T} 8$ & 7.80 & 55.72 & 15.87 & 7.19 & 11.94 & 1.48 \\
\hline & T9 & 7.69 & 59.17 & 10.46 & 6.98 & 13.77 & 1.94 \\
\hline & $\mathrm{T} 10$ & 7.93 & 57.10 & 12.54 & 7.46 & 13.14 & 1.83 \\
\hline \multirow{10}{*}{$\begin{array}{l}\text { Second } \\
\text { crop }\end{array}$} & $\mathrm{T} 1$ & 6.62 & 66.11 & 9.68 & 3.12 & 13.54 & 0.93 \\
\hline & $\mathrm{T} 2$ & 5.70 & 60.00 & 12.97 & 3.87 & 16.01 & 1.46 \\
\hline & $\mathrm{T} 3$ & 6.08 & 63.48 & 12.49 & 3.48 & 13.22 & 1.25 \\
\hline & $\mathrm{T} 4$ & 6.43 & 59.83 & 11.90 & 4.16 & 16.26 & 1.42 \\
\hline & $\mathrm{T} 5$ & 5.42 & 60.21 & 12.54 & 3.54 & 16.21 & 2.08 \\
\hline & T6 & 4.70 & 69.46 & 9.21 & 2.96 & 12.93 & 0.74 \\
\hline & $\mathrm{T} 7$ & 5.41 & 62.76 & 12.74 & 3.55 & 14.23 & 1.31 \\
\hline & $\mathrm{T} 8$ & 5.69 & 63.67 & 11.45 & 3.74 & 14.06 & 1.38 \\
\hline & T9 & 5.92 & 67.38 & 9.54 & 2.89 & 13.38 & 0.89 \\
\hline & $\mathrm{T} 10$ & 5.28 & 60.34 & 14.25 & 3.45 & 15.16 & 1.51 \\
\hline \multirow{10}{*}{$\begin{array}{l}\text { Third } \\
\text { crop }\end{array}$} & $\mathrm{T} 1$ & 5.87 & 64.89 & 10.91 & 4.76 & 12.12 & 1.45 \\
\hline & $\mathrm{T} 2$ & 6.97 & 65.20 & 9.24 & 4.41 & 13.07 & 1.11 \\
\hline & $\mathrm{T} 3$ & 7.38 & 65.94 & 9.93 & 4.07 & 11.48 & 1.20 \\
\hline & $\mathrm{T} 4$ & 8.15 & 63.04 & 10.11 & 4.12 & 13.60 & 0.97 \\
\hline & $\mathrm{T} 5$ & 7.16 & 65.33 & 9.50 & 4.95 & 11.97 & 1.09 \\
\hline & T6 & 7.70 & 61.66 & 9.55 & 5.80 & 13.76 & 1.53 \\
\hline & $\mathrm{T} 7$ & 8.47 & 57.42 & 14.21 & 4.75 & 13.51 & 1.63 \\
\hline & T8 & 8.40 & 55.50 & 15.61 & 5.86 & 13.51 & 1.13 \\
\hline & T9 & 7.79 & 59.01 & 12.69 & 5.92 & 13.18 & 1.41 \\
\hline & $\mathrm{T} 10$ & 7.49 & 60.36 & 11.56 & 5.26 & 13.52 & 1.81 \\
\hline
\end{tabular}

\section{Discussion}

\subsection{Biomass and phosphorus absorption of waxy maize treated with different conditioners}

The results of this test showed that combined with the three stubble biomass and phosphorus nutrient absorption, T2 (humic acid) and T10 (humic acidbiochar-bentonite-alum-dephosphorized gypsum) were beneficial to the growth of waxy corn and phosphorus in soil Vegetarian absorption. Some research results showed that humic acid could enhance plant respiration 
by improving the respiration activity of plants and improving the function of chloroplasts and mitochondria [27-29] to promote the growth of plants above ground, and the application of humic acid could improve soil permeability and soil fertility to promote the absorption of phosphorus in soil by crops ${ }^{[30,31]}$. In this experiment, humic acid was applied to both $\mathrm{T} 2$ and T10 treatments and showed the advantage of increasing the biomass and phosphorus absorption of waxy corn, this was the same as previous studies. However, from the results of the three crops, there was no significant difference between the treatments after the conditioner was applied in the first crop, which might be due to the short application time of the conditioner, and the absorption effect on waxy corn was not obvious. Among the results of the second and third crops, T2 (humic acid) was the best for the second crop, and T10 (humic acid-biochar-bentonitealum-dephosphorized gypsum) was used for the third crop. The best combination effect might be due to the effect of the second crop as a nutritive conditioning agent humic acid, which significantly increased the biomass and phosphorus absorption of waxy corn, but because there was no external phosphorus application for a long time, in the third crop single application humic acid can no longer meet the demand for waxy corn growth, and other conditioning agents were needed. Biochar and bentonite had adsorption ${ }^{[32-35]}$. Alum and dephosphorized gypsum could fix phosphorus in the soil $[12,36]$. Humic acid activated phosphorus adsorbed and fixed in soil ${ }^{[37,38]}$ and later promoted the absorption of phosphorus by waxy corn.

\subsection{Effect of different treatments on soil phosphorus}

To some extent, Soil available phosphorus could express the degree of phosphorus absorption by crops $^{[39]}$. The available phosphorus content of the three crops was the same as that of waxy corn biomass and phosphorus absorption. After applying the conditioner, the effect of reducing soil available phosphorus was not significant in the first crop. The application of conditioners played a role in the second and third crop. T8 (humic acidbiochar-alum) and T10 (humic acid-biochar-bentonitealum-dephosphorized gypsum) was significantly lower than the control in the second crop. T8 (humic acidbiochar-alum) was the lowest than the other treatments in the third crop. The combined application of humic acid, biochar, bentonite, alum and dephosphorized gypsum did not significantly reduce soil available phosphorus in the third crop. It could be because that humic acid, biochar and alum, together with bentonite and dephosphorized gypsum would weaken the effect of reducing soil available phosphorus after long-term application. In the transformation of soil inorganic phosphorus and organophosphorus, from the proportion of inorganic phosphorus and organophosphorus in the total phosphorus of soil, the three results showed that soil organic phosphorus was transformed to inorganic phosphorus. The treatments with the conditioners were compared with the control, except T3,T5 and T8 treatments all slowed down the conversion of soil organic phosphorus to highly effective form and reduced the movement of phosphorus. As for the results of studies on the transformation of soil inorganic phosphorus, some studies believed that $\mathrm{Ca}-\mathrm{P}$ was the main body of soil available phosphorus pool, $\mathrm{Ca}_{2}-\mathrm{P}$ was the most active component, and $\mathrm{Ca}_{8}-\mathrm{P}$ plays an important role in regulating soil available phosphorus pool [39], and the results of this test indicated that the ratio of $\mathrm{Ca}_{8}-\mathrm{P}$ in the inorganic phosphorus component of the test soil was the largest, reaching about $50 \%$ to $60 \%$.

\section{Conclusions}

(1)Based on the analysis of biomass and phosphorus absorption of three crops of waxy corn, except that the effect of the first crop was not significant, biomass and phosphorus absorption of waxy corn of T2 (humic acid) was the highest in the second crop and that of T10 (humic acid-biochar-bentonite- alum-dephosphorized gypsum) was the highest in third crop, which was $47.8 \%$ and $58.38 \%$ higher than the control. The single application of humic acid promoted the biomass and phosphorus absorption of waxy corn in the second crop. The combined application of humic acid, biochar, bentonite, alum and dephosphorized gypsum had the best effect in the third crop.

(2)The soil available phosphorus content of T8 (humic acid-biochar-aluminum) was the lowest in the second crop, and that of T10 (humic acid-biocharbentonite-alum-dephosphorized gypsum) was lowest in the third crop ,which decreased by $12.01 \%$ and $12.75 \%$ compared with the control. The soil water-soluble phosphorus content of T4 (bentonite) was lowest in the first crop, which was $41.84 \%$ lower than the control, and that of T8 (humic acid-biochar-alum) was the lowest, which was $26.62 \%$ lower than the control. Among the ratios of inorganic phosphorus and organic phosphorus to total phosphorus, according to the results of the three crops, the ratio of the total phosphorus content of the inorganic phosphorus of each treatment in the third crop was increasing compared with that of each treatment in the first crop. The soil was transformed from organic phosphorus to inorganic phosphorus. The proportion of organic phosphorus in total phosphorus content of T6 (dephosphorized gypsum), T9 (humic acid - biochar bentonite - alum), and T10 (humic acid - biochar bentonite - alum - dephosphorized gypsum) was larger than that of other treatments, the three treatments slowed down the transformation of phosphorus to effective form. In this test, through the analysis of three crops, $\mathrm{Ca}_{8}-\mathrm{P}$ accounted for the largest ratio of inorganic phosphorus component in the soil, reaching about $50 \%$ to $60 \%$. The combined application of humic acid, biochar, alum and the combined application humic acid, biochar, bentonite, alum, dephosphorized gypsum was beneficial to slow the transformation of phosphorus to an effective state, reduce potential phosphorus environmental risks, and improve the reduction of phosphorus environmental issues in greenhouse farmland. 


\section{Acknowledgments}

This work was financially supported by 'Study on the influence factors of high-efficiency growth of characteristic crops and the optimization model of supporting cultivation techniques' of 'University leadership training program' project in Tianjin(J010090 30705), Tianjin key R \& D plan scientific and technological support key project 'Integrated control and application of integrated environmental risks of nitrogen and phosphorus in protected farmland and soil quality improvement technology '(19YFZCSN00290), and national key R \& D project 'Integrated demonstration of soil remediation and pollution control technology for high nitrogen and phosphorus residues'(2016YFD08010 06). Thanks for the support of these projects.

\section{References}

1. S.S. Lu, C.G. Jiang. Acta Agr. Sinica, 27 (2012)

2. S. Kuo, B. Huang, R. Bembenek. Biology and Fertility of Soils.41 (2005)

3. L. Blake, A.E. Johnston, P.R. Poulton, K.W.T. Goulding, Plant and Soil.254(2003)

4. C.Y. Li ,S.C. Lu. Journal of Tianjin Agricultural University.26(2019)

5. Y. Zhai, Q.Su, W.X. Xu, Z.A. Hou, Chinese, Joumal of Soil Science.45 (2014)

6. B. Fang, X.Q. Li, B. Zhao, L. Zhong,Eco. and Environmental Sciences,23(2014)

7. A. Obia, J. Mulder, V. Martinsen, G. Cornelissen, T. Børresen, Soil and Tillage Research.155(2016)

8. S. Wang, J. Shan, Y. Xia, Science of The Total Environment,593(2017)

9. Y. Zheng, L. Zhou, J.H. Liu, Chinese Journal of Ecology,(2019)

10. W. Liu, H. Ji, P. Kerr, Y.H. Wu, Y.M. Fang, Env Sci.\&Poll. Res,22( 2015)

11. H.L. Ji, R. Yan, Y.D. Li, Y.M. Fang, L.Z. Yang, Y.H. Wu,Soils,43(2011)

12. A. Mishra, M.L. Cabrera, J.A. Rema, Soil Use and Management,28 (2012)

13. Z.Y. Zhang, Humic Acid,3(1993)

14. H. Yang, Y.S. Li, Y.G. Zhang, Coalification,36 (2013)

15. Z.D. Zhang, X.H. Li, J. Zhang, Y.R. Gao, P. Wan. Journal of Soil and Water Conservation,30(2016)

16. M. Schenk, B. Heins, B. Steingrobe, Plant and Soil,135(1991)

17. S.D. Bao, Agrochemical Analysis of Soil (3rd Edition).(Beijing: China Agr. Press, 2000)

18. Y.C. Gu, S.W. Qin, Soil,29(1997)

19. Y.P. Zhang, Y. Li, P.H. Nie, M. Sun, B.M. Gao, Z.H. Liu, Bulletin of Chinese agr.23(2007)

20. Z.G. Zhou, L.M. Xiong, Chinese Journal of Soil Science,29(1998)

21. A.M. Atia, A. P. Mallarino, Soil Science Society of America Journal,66(2002)

22. Q.Y. Cai, X.Z. Zhang, T.X. Li, G.D. Chen, Chinese
Journal of Applied Ecology,25(2014)

23. Y.P. Wu, X.Z. Zhang, T.X. Li, X.B. Yang, D.Y. $\mathrm{Wu}$, Jaurual of Nuclear Agricultural Sciences, 27(2013)

24. B. Zhang, F. Fang, Y.P. Chen, Acta Sci.Cir,32 (2012)

25. R.K. Lu, Chemical analysis method of soil agriculture. Beijing: China Agricultural Science and Technology Press,(1999)

26. H.F. Liu, Effects of seaweed extracts on the morphology and availability of phosphorus in red soil,(Beijing: Thesis of Chinese Academy of Agricultural Sciences,2007)

27. A. Muscolo, M. Sidari, E. Attina, O. Francioso, Soil Science Society of America Journal,71(2007),.

28. D.S. Orlov, L.K. Sadovnikova, Use of humic substances to remediate polluted environments: from the ory to practice,(Springer Netherlands, 2005)

29. S. Trevisan, O. Francioso, S. Quaggiotti, Nardi. Plant Signaling and Behavior,5(2010)

30. V. Mora, E. Bacaicoa, A.M. Zamarreo, E. Aguirre, M. Garnica, M. Fuentes, J.M. Garca-Mina, S.W. Zhang, X.P. Zhou. Journal of Plant Physiology, 167(2010)

31. K.H. Brown, E.A. Bach, R.A. Drijber, Global Change Biology,20(2014)

32. S. Zhang, X.J. Zhang, Y. Zhao, Y.H. Zhang, Q. $\mathrm{Hu}$, Y.L. Jing, J.G. Fu, Jiangsu J.of Agr.Sci,5(2019)

33. C.R. Ma, X.C. Zhang, P. Wang. Environmental Chemistry,38(2019)

34. Z. Wang, W.R. Lan, L.A. Deng, J.R. Li, X.G. Huang, Journal of Wuhan Institute of Technology,41(2019)

35. J.J. Zhang, Y.Q. Zhao, L. Xu, D.L. Hua, Q.Y. Yang,Soience of Soil and Water Conservation, 17(2019)

36. J. Zhu, B.Q. Fan, B.B. Gao, Q. Chen, Journal of Agro-Environment Science,37(2018)

37. S.Q. Zhang, L. Yuan, Z.A. Lin, Y.T. Li, S.W. Hu, B.Q. Zhao, Journal of Plant Nutrition and Fertilizer,23(2017)

38. J. Li, L. Yuan, B.Q. Zhao, Y.T. Li, Y.C. Wen, W. Li, Z.A. Lin, Journal of Plant Nutrition and Fertilizer,23(2017)

39. X. Cao, H.M. Zang, Y.L. Zhao, W.M. Xiu, G. Li, D.L. Yang, H.F. Liu, J.N. Zhao, Journal of AgroEnvironment Science,34(2015)

40. K.C. Uzoma, M. Inoue, H. Andry, H. Fujimaki, Soil Use and Management,27(2011) 